\title{
Is cattle grazing more important than landscape heterogeneity for grasshoppers in Afromontane grassland?
}

\author{
Lize Joubert-Van der MerWe', James S. Pryke'
}

1 Department of Conservation Ecology and Entomology, Stellenbosch University, Matieland, South Africa.

Corresponding author: Lize Joubert-van der Merwe (lizejoubert@gmail.com)

Academic editor: Corinna S. Bazelet | Received 12 June 2017 | Accepted 19 December 2017 | Published 12 June 2018

http://zoobank.org/2E6A3571-AD95-40A9-9886-51A128339C76

Citation: Joubert-van der Merwe L, Pryke JS (2018) Is cattle grazing more important than landscape heterogeneity for grasshoppers in Afromontane grassland? Journal of Orthoptera Research 27(1): 13-21. https://doi.org/10.3897/jor.27.15027

\begin{abstract}
Overgrazing is a major driver of habitat degradation, especially in southern Africa. Although grasshoppers are adapted to and benefit from natural disturbances, such as grazing by indigenous game and burning, we do not know how they respond to heavy cattle grazing, and how this response interacts with different fire regimes. We also do not know whether grasshoppers respond principally to these disturbances, to changes in the vegetation layer, or to larger landscape attributes (e.g. elevation). We addressed these questions in the topographically heterogeneous Central Midlands of KwaZulu-Natal Province, South Africa. We compared grasshopper assemblages among sites differing in grazing intensity (light, moderate and heavy), fire regime, rocky outcrops and vegetation structure, and attributes of landscape heterogeneity. The local environment (rocky outcrops, bare ground cover, grass height and total vegetation cover) was more important than landscape attributes for all measures of diversity. Grasshopper species richness was best explained by grazing intensity, with the specific response determined by fire regime. Greatest species richness was consistently recorded in heavily-grazed grassland. Thus, we found no evidence in support of the Intermediate Disturbance Hypothesis. Grasshopper assemblage composition of areas with light grazing was different from those with heavy grazing, but areas with light grazing were similar to those with moderate grazing under all fire regimes. Different suites of grasshopper species were adapted to changes in the local environment, with greatest diversity (Shannon $\mathrm{H}^{\prime}$ ) associated with elevated levels of bare ground and sparse vegetation cover. The greatest proportion of rare, endemic and sensitive grasshoppers (incl. Lentula minuta, Machaeridia conspersa and Qachasia fastigiata) was associated with a greater proportion of vegetation cover. The sensitivity of grasshopper assemblages to fire-grazing interactions, and the habitat requirements of different suites of species necessitates consideration of different types (fire and grazing) as well as levels of disturbances when adjusting management practices. We recommend that conservation of rare, endemic and sensitive grasshoppers should be prioritized, as these are most vulnerable to local extirpation.
\end{abstract}

\section{Key words}

assemblage composition, burning regime, elevation, Grasshopper Conservation Index (GCI), grazing intensity, indicators, landscape heterogeneity, plants, Shannon diversity $\left(\mathrm{H}^{\prime}\right)$, species richness, topographic position, vegetation structure

\section{Introduction}

Fire and grazing by indigenous large ruminant mammals are natural disturbances in Afromontane grassland, which is one of several consumer-controlled grasslands in the world (Bond et al. 2003, Bond and Keeley 2005). Natural disturbances maintain favorable conditions for species coexistence of stationary taxa, such as plants (Chesson 2000). The exclusion of fire causes grassland plant assemblages to change in composition and become speciespoor (Pausas and Ribeiro 2017), especially in an African context (Kirkman et al. 2014). Grazing interacts with fire to change the richness and structure of the vegetation layer (Burkepile et al. 2016, Joubert et al. 2017), which then influences arthropod assemblages (Joern and Laws 2013). Superimposed upon these effects of disturbances and disturbance interactions on biodiversity are large-scale spatial and temporal phenomena, such as landscape fragmentation (Stoner and Joern 2004, Krauss et al. 2010), landscape heterogeneity (Batáry et al. 2007), seasonal changes (Fonderflick et al. 2014) and weather cycles (Jonas and Joern 2007). It is necessary to identify drivers with large effects on biodiversity, and to understand how they relate with one another in natural landscapes in order to implement appropriate and effective conservation interventions.

Not all of biodiversity responds similarly to drivers of natural landscapes. Patterns in plant assemblages often show a lag in response to changes in the landscape, but respond quite rapidly to changes in the local environment (Krauss et al. 2010, Joubert et al. 2016a). Herbivorous arthropods respond more frequently and consistently to local changes in the vegetation layer than to changes in the landscape, while predatory arthropods respond more frequently to landscape than to local changes in vegetation structure (Collinge et al. 2003, Stoner and Joern 2004, Torma et al. 2014). Due to the taxonomic challenge and sheer numbers of insects (Cardoso et al. 2011), especially in sub-tropical grasslands, it is important to select indicators to represent biodiversity's response to ecosystem and environmental change (McGeoch 1998, Gerlach et al. 2013).

Grasshoppers are often used as indicators of grassland quality (Gerlach et al. 2013). This is because they are taxonomically well- 
known and ecologically sensitive, they respond reliably to changes in their local environment (Bazelet and Samways 2011a) and they mimic the response of other invertebrate groups, e.g. butterflies (Marini et al. 2009, Bazelet and Samways 2012). As primary consumers, grasshoppers show greater response to local attributes than to changes in the landscape (Marini et al. 2007, Bazelet and Samways 2011b), but this may vary (Batáry et al. 2007). Grazing influences grasshoppers directly (e.g. mortality due to trampling or unintentional ingestion) and indirectly via the effect of cattle grazing on vegetation structure and specific plant assemblage (Joern 2005, Marini et al. 2009, Joubert et al. 2016b). In a global review of arthropod response to large grazing mammals, it was concluded that arthropod diversity only increases in grazed ecosystems if increased heterogeneity of the biotic and abiotic environment outweigh loss of resources and increased mortality (Van Klink et al. 2015).

Afromontane grassland is conserved in formally protected areas as well as Ecological Networks (ENs) among forestry plantations in South Africa (Samways and Pryke 2016). The conservation and management of heterogeneity at the local and landscape spatial scale is central to the success of grassland ENs (Pryke et al. 2013). Design of ENs should incorporate the typical landscape heterogeneity found in the region (Pryke and Samways 2015), while management should avoid homogenization of grassland habitat by incorporating a patch mosaic burning regime (Bazelet and Samways 2011b, Joubert et al. 2016b) and encouraging grazing by indigenous game (Pryke et al. 2016). However, in ENs where domestic cattle replaced indigenous animals as dominant grazers, it is not clear how grasshoppers respond to different intensities of grazing. We also do not know whether grasshoppers respond primarily to these natural disturbances, to changes in the local biotic environment caused by these disturbances, or landscape heterogeneity.

The aim of this paper is to determine the main drivers of grasshopper assemblage composition, diversity and species richness in Afromontane grasslands. Are grasshoppers influenced mostly by grazing intensity, or phenomena at the local or landscape spatial scale? We hypothesize that grazing intensity and the local environment will have a larger effect than larger scale phenomena, because these small herbivores are sensitive to local changes in microclimatic niches, oviposition sites, and shelter from predators. Secondly, we hypothesize that grasshopper diversity will peak at intermediate levels of disturbance, as observed in the literature (Van Klink et al. 2015). Here, we also wish to identify indicator species of different grazing regimes. Thirdly, we expect different measures of grasshopper diversity to correlate with one another, as they correlated with other taxonomic groups (Bazelet and Samways 2012). Answering these questions will help us decide upon conservation action, specifically where it involves grasshoppers in ENs within transformed landscapes.

\section{Methods}

Description of study area. - The study took place in the mid-elevational grasslands (1168-1573 m a.s.l.) east of the Drakensberg mountain range in KwaZulu-Natal Province, South Africa. It is a summer rainfall area, with precipitation mostly in the form of thunderstorms and mist in summer, with mean annual precipitation of $\sim 1120 \mathrm{~mm}$. The topography is variable, and so are the vegetation patterns. Grasslands co-occur with natural wetlands in depressions and indigenous forest patches in steep valleys.
Anthropogenic changes to the disturbance regime.-Fire and grazing are natural disturbances in these landscapes (Bond et al. 2003), but their frequency and intensity have changed greatly in response to change in anthropogenic land uses. Domestic livestock replaced indigenous game as dominant grazers, following the introduction of husbandry practices 2000 years BP, and the influx of European settlers since the early $19^{\text {th }}$ century (Deacon and Deacon 1999). Concurrently, the intensity of grazing increased (Rowe-Rowe and Scotcher 1986), impacting upon fuel load and spread of fire. Changes in land use from natural grasslands to agricultural crops (e.g. maize) and alien tree plantations further drove changes in the fire regime, as land users adapted fire as a tool for managing these novel landscapes. The current fire regime is more homogeneous than in the past due to legislative and organizational constraints that attempt to balance risks and benefits to commercial enterprises and remaining natural habitat.

Site selection and classifications. - Sites $(n=68)$ were in a large-scale EN in the Mt Shannon and Good Hope Forestry Estates, as well as in the adjacent Protected Area (PA), iMpendle Nature Reserve (Fig. 1). The variability in topography and disturbance regimes (found among sites) is representative of the variability found in the larger landscape. There were differences in abiotic landscape attributes (topographic position, elevation and aspect), or the local environment (rocky outcrops and vegetation structure).

Fire frequency was classified as either annual burning $(\mathrm{AB})$ or longer fire rotations (LFR). Time since last fire at LFR sites were classified as recently-burned (RB) i.e. burned $<12$ months prior to sampling vs. unburned (UB) i.e. burned $>12$ months prior to sampling (Table 1). Grazing intensity at each site was categorized as light (reference sites in the PA), and moderate or heavy in the EN. Classification of sites was based on indicators of historical grazing (dominant grass composition and aerial cover by poisonous forbs - Senecio isatideus or S. retrorsus) and current grazing (grass height, bare ground due to trampling, and occurrence of cattle) (Joubert et al. 2017).

Sampling procedure.-Sites were $>400 \mathrm{~m}$ apart to allow for independence of sampling. Except for annually-burned sites in narrow $(<50 \mathrm{~m})$ corridors, all sites were $>30 \mathrm{~m}$ from forestry compartment edges in the interior of wider ( $>150 \mathrm{~m}$ ) corridors. At each site, we sampled the grasshoppers three times: late spring (November 2012), mid-summer (January 2013), and early autumn (March 2013) with sweep nets. This involved sweeping a net (diameter: $400 \mathrm{~mm}$; mesh size: $2 \mathrm{~mm}$ ) back and forth in an $180^{\circ}$ arch. There was one sweep with each step along four $100 \mathrm{~m}$ long transects that were spaced parallel to one another and $5 \mathrm{~m}$ apart; thus, 400 sweeps per sampling season and 1200 sweeps per site. Data from the three sampling seasons were pooled for analyses. Nets were emptied after every 25-30 sweeps to prevent escape of agile species. Grasshoppers were frozen, sorted and identified to the lowest possible taxonomic level (Dirsh 1965, Johnsen 1984, Johnsen 1991, Cigliano et al. 2017).

For the local environment, we recorded vegetation attributes at each site. Plant assemblage composition outperforms vegetation structure at predicting response of different functional groups of arthropods (Schaffers et al. 2008), including grasshoppers (Kemp et al. 1990). However, vegetation structure and host plant diversity hinges upon the contribution of individual plant species (Joern and Laws 2013), especially in an African context (Gandar 1982). Therefore, using plant species richness and measures of vegetation structure as a proxy for change in the vegetation layer is justified. 


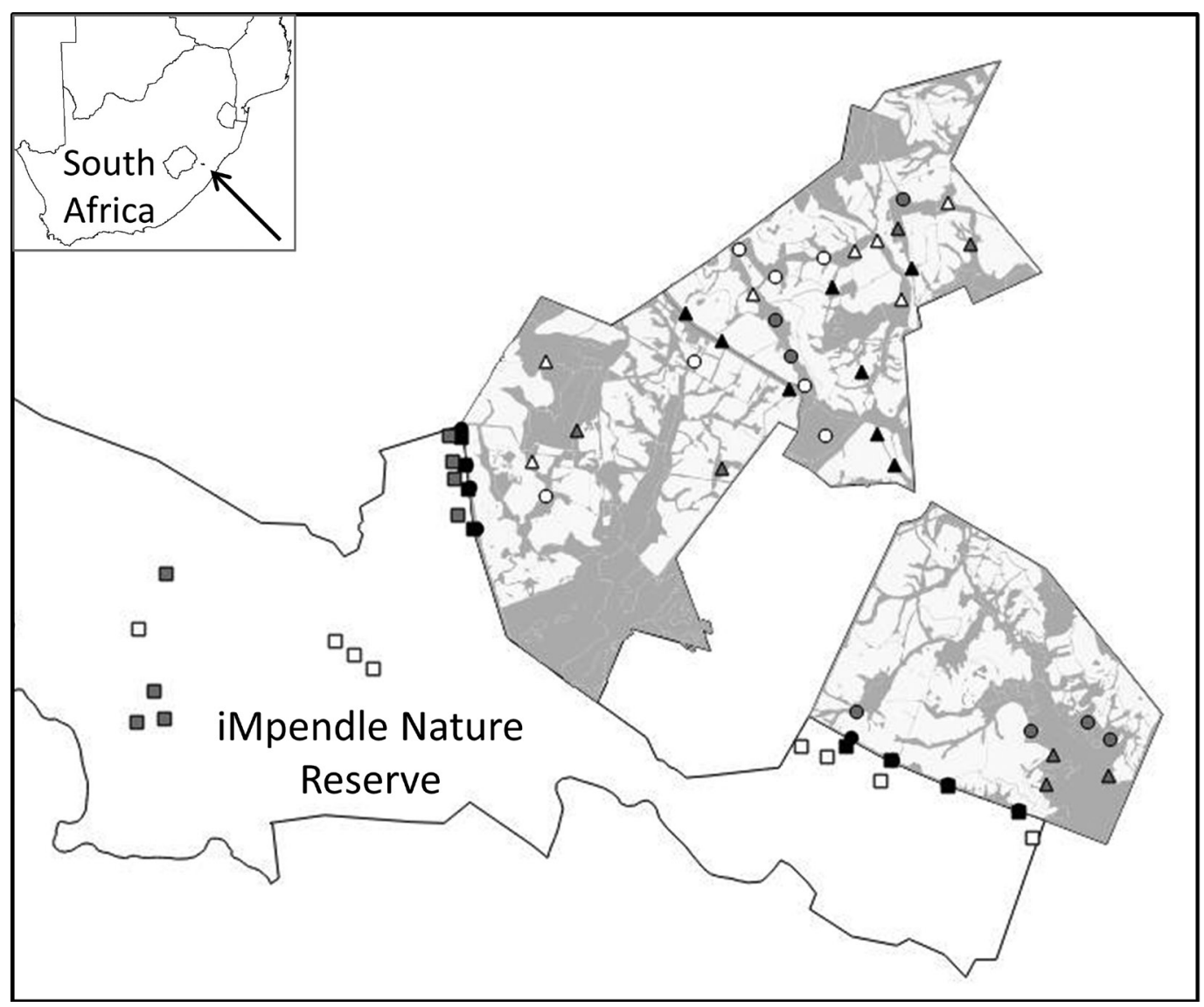

AB-Light - AB-Moderate A AB-Heavy

RB-Light

RB-Moderate $\triangle$ RB-Heavy $\square$ UB-Light
$\bigcirc$ UB-Moderate
$\triangle$ UB-Heavy

Fig. 1. Map of study sites in the KwaZulu-Natal Midlands. Abbreviations for grazing intensity: light in iMpendle Nature Reserve (square symbols), and moderate (circular symbols) or heavy (triangular symbols) in the ecological network. Abbreviations for fire regime: annual burning ( $\mathrm{AB}$, solid black symbols), grasslands with longer fire rotation that were recently-burned (RB, solid grey symbols) i.e. burned $<12$ months prior to sampling and unburned (UB, open symbols) i.e. burned $>12$ months prior to sampling.

Table 1. Description of the grazing and fire regime in each group of sites. Abbreviations for grazing intensity: light in the protected area (PA), and moderate or heavy in the ecological network. Abbreviations for fire regime: annual burning, grasslands with longer fire rotation that were recently-burned (i.e. burned $<12$ months prior to sampling) and unburned (i.e. burned $>12$ months prior to sampling).

\begin{tabular}{ccccc}
\hline Fire frequency & $\begin{array}{c}\text { Time since } \\
\text { last fire }\end{array}$ & $\begin{array}{c}\text { Fire } \\
\text { abbreviation }\end{array}$ & $\begin{array}{c}\text { Grazing } \\
\text { intensity }\end{array}$ & $\begin{array}{c}\text { Sample } \\
\text { size (n) }\end{array}$ \\
\hline Annual burning & Recently-burned & $\mathrm{AB}$ & Light (PA) & 8 \\
Annual burning & Recently-burned & $\mathrm{AB}$ & Moderate & 8 \\
Annual burning & Recently-burned & $\mathrm{AB}$ & Heavy & 8 \\
Longer fire rotations & Recently-burned & $\mathrm{RB}$ & Light (PA) & 8 \\
Longer fire rotations & Recently-burned & $\mathrm{RB}$ & Moderate & 7 \\
Longer fire rotations & Recently-burned & $\mathrm{RB}$ & Heavy & 7 \\
Longer fire rotations & Unburned & $\mathrm{UB}$ & Light (PA) & 8 \\
Longer fire rotations & Unburned & $\mathrm{UB}$ & Moderate & 7 \\
Longer fire rotations & Unburned & $\mathrm{UB}$ & Heavy & 7 \\
\hline
\end{tabular}

At each site $\left(\sim 1000 \mathrm{~m}^{2}\right)$, we recorded vegetation attributes in 24 discontinuous vegetation quadrats $\left(1 \mathrm{~m}^{2}\right)$ and six transects (i.e. six transects $\times 30 \mathrm{~m}=180$ measurements) (Joubert et al. 2017). In quadrats, we recorded vegetation cover of all plants (i.e. total veg- etation cover), vegetation cover by only grasses (i.e. only grass cover), bare ground cover, rocky outcrop cover, and cumulative plant species richness in vegetation quadrats. The cumulative plant species richness of 24 discontinuous vegetation quadrats was used as a proxy for plant species richness of the whole site $\left(1000 \mathrm{~m}^{2}\right)$ (Güler et al. 2016). Vegetation quadrats were spaced evenly along vegetation transects. Along transects, we recorded vegetation height and basal distance at $1 \mathrm{~m}$ intervals. Basal distance serves as a proxy for trampling and erosion potential, especially on steep slopes, and measured as the distance from the bottom of a vertical rod (diameter: $15 \mathrm{~mm}$ ) to where the nearest plant was rooted. Table 2 summarizes the differences in vegetation structure for each grazing intensity class. Transects were connected end-to-end, with orientation of each transect determined randomly. Averages were calculated for all attributes of the vegetation layer, except for $\mathrm{cu}$ mulative plant species richness. Lastly, we recorded the following landscape parameters for each site: topographic position (footslope/valley bottom, midslope, and crest/ridge/escarpment), elevation and aspect.

Calculation of the Grasshopper Conservation Index.-The Grasshopper Conservation Index (GCI) estimates conservation value of a site based on occurrence of grasshopper species with specific traits related to extinction risk and sensitivity to habitat change. The standardized GCI site score (GCIn) is the sum of all GCI scores of spe- 
Table 2. Vegetation structure in each disturbance category. Abbreviations for grazing intensity: light (L) in the protected area, and moderate $(\mathrm{M})$ or heavy $(\mathrm{H})$ in the ecological network. Abbreviations for fire regime: annual burning (AB), grasslands with longer fire rotation that were recently burned (RB; i.e. burned $<12$ months prior to sampling) and unburned (UB; i.e. burned $>12$ months prior to sampling).

\begin{tabular}{|c|c|c|c|c|c|c|}
\hline & Bare ground cover (\%) & Vegetation cover (\%) & Only grass cover $(\%)$ & Rock cover (\%) & Vegetation height $(\mathrm{cm})$ & Basal distance $(\mathrm{cm})$ \\
\hline $\mathrm{AB}-\mathrm{L}$ & $3.50 \pm 0.85$ & $95.75 \pm 1.03$ & $65.50 \pm 2.04$ & $0.75 \pm 0.47$ & $38.13 \pm 2.97$ & $0.58 \pm 0.04$ \\
\hline AB-M & $5.25 \pm 1.11$ & $93.88 \pm 1.04$ & $65.13 \pm 1.42$ & $1.15 \pm 0.84$ & $28.38 \pm 2.65$ & $0.53 \pm 0.04$ \\
\hline $\mathrm{AB}-\mathrm{H}$ & $16.13 \pm 3.38$ & $81.75 \pm 2.95$ & $60.50 \pm 2.72$ & $2.00 \pm 1.94$ & $28.38 \pm 3.20$ & $0.94 \pm 0.09$ \\
\hline RB-L & $5.50 \pm 0.98$ & $87.75 \pm 2.38$ & $57.13 \pm 1.46$ & $7.08 \pm 2.29$ & $36.13 \pm 1.84$ & $0.98 \pm 0.1$ \\
\hline RB-M & $4.29 \pm 1.69$ & $89.29 \pm 3.96$ & $57.57 \pm 4.49$ & $6.61 \pm 4.21$ & $47.14 \pm 8.20$ & $0.90 \pm 0.11$ \\
\hline RB-H & $10.86 \pm 3.25$ & $86.57 \pm 3.11$ & $59.86 \pm 3.00$ & $2.60 \pm 1.94$ & $30.00 \pm 4.35$ & $0.82 \pm 0.1$ \\
\hline UB-L & $1.00 \pm 0.76$ & $91.88 \pm 2.99$ & $70.75 \pm 3.50$ & $1.38 \pm 0.72$ & $45.88 \pm 1.65$ & $2.58 \pm 1.64$ \\
\hline UB-M & $1.43 \pm 0.81$ & $94.29 \pm 1.6$ & $63.71 \pm 1.51$ & $3.99 \pm 1.96$ & $40.00 \pm 1.72$ & $0.79 \pm 0.05$ \\
\hline UB-H & $5.86 \pm 2.16$ & $92.29 \pm 2.86$ & $69.14 \pm 3.37$ & $1.27 \pm 0.85$ & $38.57 \pm 6.69$ & $0.83 \pm 0.11$ \\
\hline
\end{tabular}

cies present at that site divided by grasshopper species richness for that site. GCI species scores were calculated for each grasshopper species by adding up the values of individual criteria: geographic distribution, mobility and rarity (Matenaar et al. 2015). Scores for geographic distribution were: 1) occurrence outside of South Africa, 2) endemic to South Africa, and 3) endemic to one province. Scores for dispersal capacity were: 1) fully capable of flight, 2) wings dimorphic, and 3) flightless. Scores for rarity were: 1) common (i.e. present in $>15$ sites), 2) intermediate (i.e. present in 8-15 sites), and 3) rare (i.e. present in $\leq 7$ sites). Values for species were taken from published literature (Bazelet and Samways 2012, Adu-Acheampong et al. 2016). Where grasshoppers in our dataset were not identified to species-level, the geographic distribution was recorded as one ( = 1 ). All analyses were conducted on the standardized GCI site score.

Data analyses. - We determined whether grasshopper assemblages were influenced by 1) landscape parameters, 2) the local environment, or 3) grazing intensity when viewed within the context of a certain fire regime (from here onwards referred to as just 'grazing intensity'). Landscape parameters were elevation, topographic position and aspect. The local environment comprised of rocky outcrops, total vegetation cover, only grass cover, vegetation height, basal distance, and bare ground cover.

We tested for the effect of these variables on grasshopper species richness, Shannon $\mathrm{H}^{\prime}$ diversity, the standardized grasshopper conservation index (GCIn) (Matenaar et al. 2015) and grasshopper assemblage composition. We calculated Shannon $\mathrm{H}^{\prime}$ diversity using the vegan package in R statistical software (version 3.2.5).

Grasshopper species richness, Shannon $\mathrm{H}^{\prime}$ diversity, and GCIn data were normally distributed. Hence, data were analyzed with General Linear Models using the lme4 package in R statistical software (version 3.2.5). We used the automatic model selection function glmulti in the package glmulti to select the best model (Calcagno and De Mazancourt 2010). Model selection was based on grazing intensity, all local attributes and landscape parameters. Where grazing intensity was included in the best model, we used Tukey post-hoc tests to conduct pairwise comparisons among grazing intensity classes. Lastly, we used Spearman's rank coefficient (rho) to test for relationships among attributes of vegetation structure, rock cover and elevation, as existence of such relationships influences interpretation of research findings.

Good indicators need to represent biodiversity's response to ecosystem and environmental change (McGeoch 1998, Gerlach et al. 2013). Using Spearman's rank coefficient (rho) in the hmisc package in $\mathrm{R}$ statistical software, we tested whether any of the measures of grasshopper diversity (species richness, Shannon $\mathrm{H}^{\prime}$ diversity, and GCIn) represented changes in plant species richness. Then, we tested for any correlations among different measures of grasshopper diversity using the same method, because we did not want to assume a linear relationship among variables (Hauke and Kossowski 2011). Finally, we used the indicator value (IndVal) method in the labdsv package of R (Dufrene and Legendre 1997) to identify grasshopper indicators of grazing intensity.

Grasshopper assemblage composition was analyzed in PRIMER 6.0 software. Grasshopper data were standardized, and abundances were square root transformed to reduce the effect of dominant species. Then, a resemblance matrix was compiled based on the BrayCurtis similarity index. We used canonical analysis of principal coordinates (CAP) to visualize patterns in grasshopper assemblage composition, i.e. how it responds to grazing intensity, vegetation structure and landscape attributes. This ordination method displays sites in a multivariate space based on the calculated similarity indices, i.e. sites grouped closely together are similar, whereas widely dispersed sites are different from one another (Anderson and Willis 2003). Then, we used two statistical tests - DistLM for continuous landscape and local variables, and permutational analyses of variance (PERMANOVA) for grazing intensity (i.e. categorical data) - to determine their effects on grasshopper assemblage composition. All continuous variables were imported as environmental data. Bare ground cover, basal distance and rock cover were log transformed. Continuous environmental variables that best describe grasshopper assemblage composition were identified using DistLM with a stepwise selection procedure and AICc selection criterion. We used PERMANOVA in the same software to test for the main effect of grazing intensity, and then to conduct pairwise comparisons among grazing intensity classes.

\section{Results}

Grasshopper species richness, Shannon $H^{\prime}$ diversity and Grasshopper Conservation Index (GCIn). - In the first model with all variables, grasshopper species richness was best explained by only grazing intensity $\left(\mathrm{AICC}=342.44\right.$; Adjusted $R^{2}=0.535$, and LM, $F=10.15, P$ $<0.001)$. The greatest number of species was recorded in annuallyburned areas with heavy cattle grazing, while the lowest number of species was recorded in unburned grassland with light grazing (Fig. 2). In annually-burned and unburned grassland, grasshopper species richness increased with increasing grazing intensity (light $<$ moderate < heavy). For these fire regimes, we found significant differences between areas with light and heavy grazing (annual burning: light $<$ heavy, $\mathrm{t}=-4.16, P=0.003$; unburned: light $<$ heavy, $\mathrm{t}=-3.94, P=0.006)$. In contrast, grasshopper species richness of recently-burned areas showed a unimodal response (light 


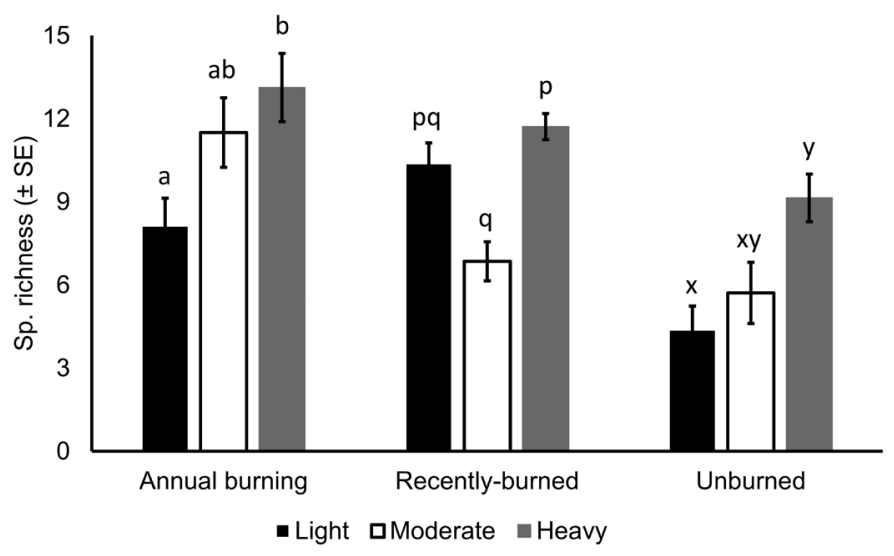

Fig. 2. Grasshopper species richness responds to grazing intensity under different fire regimes. Pairwise comparisons among grazing intensity classes (light, moderate and heavy) for annually-burned firebreaks and grasslands with longer fire rotations that were recently-burned i.e. $<12$ months prior to sampling and unburned i.e. burned $>12$ months prior to sampling. Bars with the same letters are not significantly different from one another.

$>$ moderate $<$ heavy) to increasing grazing intensity. For recentlyburned areas, species richness of moderate-grazed areas was significantly less than in heavily-grazed areas $(\mathrm{t}=-3.46, P=0.026)$.

Out of all variables, Shannon $\mathrm{H}^{\prime}$ diversity was best explained by the local environment (Shannon's diversity index, $\mathrm{AICc}=$ 53.07; Adjusted $R^{2}=0.175$, and $\mathrm{LM}, F=5.66, P=0.001$ ), but not grazing intensity. There were significant increases in Shannon $\mathrm{H}^{\prime}$ diversity, as rocky outcrops $(F=7.66, P=0.007)$ and bare ground cover $(F=5.58, P=0.02)$ increased, and a near-significant increase as vegetation cover decreased $(F=3.74, P=0.058)$.

The standardized GCI score per site (GCIn) was indicative of the proportion of rare, sensitive or range-restricted grasshopper species in the assemblage. Out of all variables, GCIn was best explained by total vegetation cover (AICc $=525.37$, Adjusted $R^{2}=$ 0.113 , and $\mathrm{LM}, F=9.57, P=0.003$ ). The greatest GCIn score was 7 and recorded in an unburned site with light grazing in the PA. This site had only four grasshopper individuals representing three species (Lentula minuta, Machaeridia conspersa and Qachasia fastigiata), which each had a score of 7 .

Relationships among diversity measures and environmental variables. We found a significant positive correlation between grasshopper species richness and Shannon $\mathrm{H}^{\prime}$ diversity (Spearman, Rho = $0.741, P<0.001)$. However, the standardized grasshopper conservation index (GCIn) was not significantly correlated with either grasshopper species richness (Spearman, Rho $=-0.031, P=0.800$ ) or Shannon $H^{\prime}$ diversity (Spearman, Rho $=-0.055, P=0.658$ ). Also, plant species richness was not significantly correlated with grasshopper species richness (Spearman, Rho $=-0.154, P=0.210$ ), Shannon $H^{\prime}$ diversity (Spearman, Rho $\left.=-0.045, P=0.720\right)$, or the GCIn (Spearman, Rho $=0.012, P=0.921$ ).

Environmental variables in this study were not independent of one another. There were significant correlations among several attributes of the local environment as well as larger landscape (Table 3). Elevation was significantly correlated with the local environment, i.e. rocky outcrops, bare ground cover and vegetation height (Table 3). Proportion of rocky outcrops was significantly correlated with most variables of the local environment:
Table 3. Spearman's correlation coefficient (rho) test for relationships among environmental variables. The variables were elevation, rocky outcrop cover, bare ground cover, grass cover, total vegetation cover, vegetation height and basal distance. Rho-values are listed (range: -1 to 1), with P-values in parentheses. Significant correlations in bold.

\begin{tabular}{|c|c|c|c|c|c|c|}
\hline & $\begin{array}{c}\text { Rocky } \\
\text { outcrops }\end{array}$ & $\begin{array}{l}\text { Bare ground } \\
\text { cover }\end{array}$ & $\begin{array}{c}\text { Basal } \\
\text { distance }\end{array}$ & $\begin{array}{l}\text { Grass } \\
\text { cover }\end{array}$ & $\begin{array}{l}\text { Vegetation } \\
\text { cover }\end{array}$ & $\begin{array}{c}\text { Vegetation } \\
\text { height }\end{array}$ \\
\hline Elevation & $\begin{array}{c}0.276 \\
(0.023)\end{array}$ & $\begin{array}{l}-0.291 \\
(0.016)\end{array}$ & $\begin{array}{c}-0.146 \\
(0.236)\end{array}$ & $\begin{array}{c}0.027 \\
(0.826)\end{array}$ & $\begin{array}{c}0.081 \\
(0.514)\end{array}$ & $\begin{array}{l}-0.350 \\
(0.004)\end{array}$ \\
\hline $\begin{array}{c}\text { Rocky } \\
\text { outcrops }\end{array}$ & & $\begin{array}{c}-0.291 \\
(0.016)\end{array}$ & $\begin{array}{c}0.430 \\
(0.001)\end{array}$ & $\begin{array}{c}-\mathbf{0 . 3 4 6} \\
(0.004)\end{array}$ & $\begin{array}{c}-\mathbf{0 . 3 2 8} \\
(0.006)\end{array}$ & $\begin{array}{c}0.047 \\
(0.701)\end{array}$ \\
\hline Bare ground & & & $\begin{array}{c}\mathbf{0 . 0 4 0} \\
(0.744)\end{array}$ & $\begin{array}{c}-0.243 \\
(0.043)\end{array}$ & $\begin{array}{c}-0.543 \\
(<0.001)\end{array}$ & $\begin{array}{c}-0.317 \\
(0.009)\end{array}$ \\
\hline $\begin{array}{c}\text { Basal } \\
\text { distance }\end{array}$ & & & & $\begin{array}{c}-0.481 \\
(< \\
0.001)\end{array}$ & $\begin{array}{l}-\mathbf{0 . 5 4 7} \\
(0.001)\end{array}$ & $\begin{array}{c}0.360 \\
(0.003)\end{array}$ \\
\hline Grass cover & & & & & $\begin{array}{c}0.573 \\
(0.001)\end{array}$ & $\begin{array}{c}0.137 \\
(0.265)\end{array}$ \\
\hline $\begin{array}{l}\text { Vegetation } \\
\text { cover }\end{array}$ & & & & & & $\begin{array}{c}\mathbf{0 . 2 6 1} \\
(0.032)\end{array}$ \\
\hline
\end{tabular}

Table 4. Grasshopper assemblage composition response to grazing intensity under different fire regimes. Pairwise comparisons among grazing intensity classes (light, moderate and heavy) for annuallyburned (AB) firebreaks and grasslands with longer fire rotations (LFR) that were recently-burned (RB) (i.e. < 12 months prior to sampling) and unburned (UB) (i.e. burned $>12$ months prior to sampling).

\begin{tabular}{cccc}
\hline Fire regime & Comparison & $\boldsymbol{t}$-value & $P$-value \\
\hline $\mathrm{AB}$ & Light vs. Moderate & 1.211 & 0.139 \\
$\mathrm{AB}$ & Moderate vs. Heavy & 1.152 & 0.190 \\
$\mathrm{AB}$ & Heavy vs. Light & 1.777 & $<0.001$ \\
$\mathrm{RB}$ & Light vs. Moderate & 1.207 & 0.134 \\
$\mathrm{RB}$ & Moderate vs. Heavy & 1.439 & 0.019 \\
$\mathrm{RB}$ & Heavy vs. Light & 1.742 & 0.003 \\
$\mathrm{UB}$ & Light vs. Moderate & 0.802 & 0.814 \\
$\mathrm{UB}$ & Moderate vs. Heavy & 1.047 & 0.369 \\
$\mathrm{UB}$ & Heavy vs. Light & 1.666 & $<0.001$ \\
\hline
\end{tabular}

bare ground, basal distance, grass cover and total vegetation cover. Most variables of the local environment were correlated with one another (Table 3).

Grasshopper assemblage composition.-Sites arranged along a continuum of disturbance intensity, with annually-burned and heavilygrazed sites to the left of the ordination space and unburned sites to the right (Fig. 3). Sites with heavy grazing grouped separately from sites with either light or moderate grazing. The bare ground: total vegetation cover gradient explained horizontal spread of sites along the first axis, while variation in rock and grass cover explained the vertical spread of sites along the second axis (Fig. 3). The two axes explained $15.5 \%$ and $11.5 \%$ of total variation in the dataset, respectively.

Grasshopper assemblage composition was best explained by the local environment $\left(\mathrm{AICc}=531.02\right.$; Adjusted $R^{2}=0.157$; Table 4). Specific variables with a significant effect were total vegetation cover (Pseudo- $F=2.59, P<0.001$ ), grass height (Pseudo- $F=3.13, P<0.001)$, bare ground cover (Pseudo- $F=4.33$, $P<0.001$ ), and rock cover (Pseudo- $F=2.02, P=0.015$ ).

Grazing intensity had a significant effect on grasshopper assemblage composition (Pseudo- $F=2.19, P<0.001$ ), with heavily grazed areas differing significantly from lightly grazed areas under 


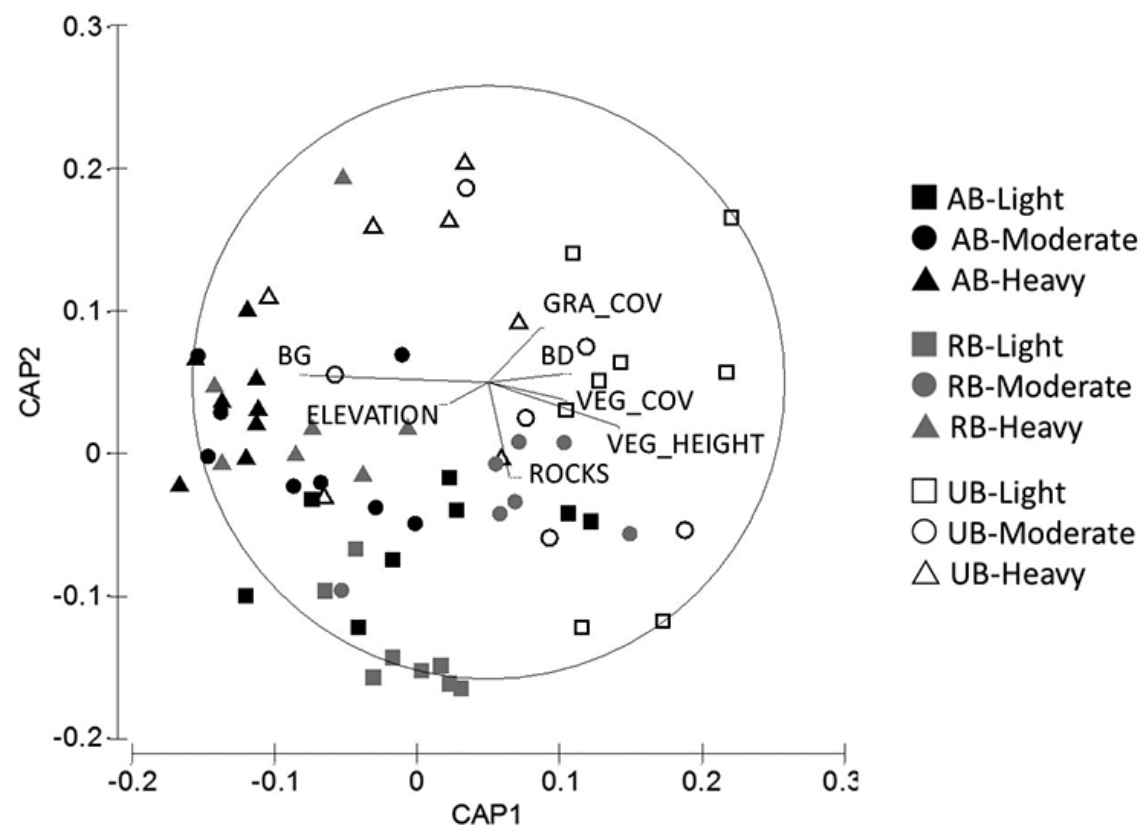

Fig. 3. Canonical analysis of principal coordinates ordination (CAP) of grasshopper assemblage composition to display patterns in the data. Abbreviations for grazing intensity: light in the protected area (square symbols), and moderate (circular symbols) or heavy (triangular symbols) in the ecological network. Abbreviations for fire regime: annual burning (AB, solid black symbols), grasslands with longer fire rotation that were recently-burned (RB, solid grey symbols) i.e. burned $<12$ months prior to sampling and unburned (UB, open symbols) i.e. burned $>12$ months prior to sampling. Significance values for pairwise comparisons are in Table 4 .

Table 5. Indicator species of grazing intensity, fire frequency, and time since last fire. Abbreviations for grazing intensity: light in the protected area, and moderate or heavy in the ecological network. Abbreviations for fire regime: annual burning (AB), grasslands with longer fire rotation that were recently-burned (RB) (i.e. burned $<12$ months prior to sampling) and unburned (UB) (i.e. burned $>12$ months prior to sampling). The GCI values of individual species, Indicator values and P-values were included.

\begin{tabular}{lcccc}
\hline \multicolumn{1}{c}{ Species } & Disturbance & GCI & Ind Val & P-value \\
\hline Anablepia pilosa & RB-Light & 6 & 0.74 & 0.001 \\
Eyprepocnemis calceata & RB-Light & 4 & 0.21 & 0.058 \\
Pseudoarcyptera cephalica & RB-Light & 6 & 0.27 & 0.017 \\
Dnopherula callosa & AB-Moderate & 4 & 0.27 & 0.013 \\
Tetrigid sp. 3 & AB-Moderate & 7 & 0.26 & 0.031 \\
Acorypha ferrifer & AB-Heavy & 4 & 0.27 & 0.025 \\
Catantops ochthephilus & AB-Heavy & 5 & 0.38 & 0.003 \\
Tetrigid sp. 1 & AB-Heavy & 5 & 0.35 & 0.009 \\
Coryphosima stenoptera subsp. & RB-Heavy & 4 & 0.33 & 0.015 \\
stenoptera & RB-Heavy & 7 & 0.30 & 0.065 \\
Lentula obtusifrons & RB-Heavy & 4 & 0.28 & 0.013 \\
Vitticatantops maculatus & UB-Heavy & 3 & 0.33 & 0.078 \\
Orthochtha sp. 2 & UB-Heavy & 6 & 0.49 & 0.001 \\
Spathosternum nigrotaeniatum & & & &
\end{tabular}

all fire regimes (Table 4). In addition, there were significant differences between moderately and heavily grazed areas that were burned recently. Under no fire regime did we find differences in composition between areas with light and moderate grazing.

We identified 13 species that were indicative of grazing intensity, of which eight species were associated with heavy grazing (Table 5). The GCI scores of two individual indicator species (Lentula obtusifrons and Spathosternum nigrotaeniatum) in heavily grazed areas were high $(\geq 6)$.

\section{Discussion}

Local versus landscape attributes. - Grasshopper assemblages responded primarily to changes in their local environment and not to larger landscape attributes. This was surprising, because earlier studies found large and significant effects of elevation and aspect on grasshopper assemblages in these mid-to-high elevational grasslands (Samways 1990, Gebeyehu and Samways 2006, Crous et al. 2013, 2014). In Afromontane grassland, grasshopper assemblage composition changed, and species richness increased with an increase in elevation (900-2200 m a.s.l.) (Crous et al. 2013). However, in Swaziland, grasshopper species richness showed the opposite response, as it declined with an increase in elevation (800-1400 m a.s.l.) (Wettstein and Schmid 1999). It is possible that the $400 \mathrm{~m}$ range in elevation in our study was not sufficient to detect this major ecological gradient. Alternatively, the effect of elevation might be explained by covariation among local and landscape attributes. There were significant correlations among landscape and local environmental attributes in our study. Our study is not unique. In the Succulent Karoo, there was sparser vegetation cover and greater grasshopper diversity on small hills (Gebeyehu and Samways 2006). Grasshopper assemblages in North America respond to large-scale and longterm environmental gradients (e.g. elevation and precipitation), but these variables are also known to correlate with changes in the local environment (Kemp et al. 1990, Jonas and Joern 2007). This is the case for calcareous and steppe grasslands in Germany (Fartmann et al. 2012, Weiss et al. 2013). Such relationships among environmental variables at the local and landscape spatial scale are a natural part of the landscape, and the reason 
why many arthropods respond indirectly to major drivers in the landscape (Joern and Laws 2013).

The effect of grazing intensity.-Grazing intensity was the most important determinant of grasshopper species richness in our study. However, the specific response of grasshopper species richness to grazing intensity (light $<$ or $>$ moderate $<$ heavy) depended on fire regime. This is because each fire regime exerts its own selection pressure on the grasshopper species assemblage (Joubert et al. 2016b), especially during the first year after fire (Little et al. 2013). The observed effect of grazing intensity is therefore on a subset of the complete species pool in these mesic grasslands. A case in point is recently-burned grassland where we found a significant response in assemblage composition and species richness when comparing moderately- and heavily-grazed areas. Such differences between moderately- and heavily-grazed areas did not exist in either annually-burned or unburned grassland. This scenario differs from a case where fire frequency and time since last fire had no such effect on grasshopper assemblage composition, causing grasshoppers to respond primarily to grazing and not to a firegrazing interaction (Joern 2005). Because grasshoppers respond to a fire-grazing interaction in our study area, it is necessary to consider both types and different levels of these disturbances when making management adjustments.

Grasshopper assemblages in heavily-grazed areas were unique in composition and more species-rich than areas with light or moderate grazing. The shift towards a more species-rich grasshopper assemblage illustrates that grasshoppers are relatively tolerant of disturbance. This includes at least one flightless, narrow-range endemic species (Lentula obtusifrons) that was an indicator of heavilygrazed areas. The high degree of tolerance to heavy cattle grazing came as a surprise, although we knew beforehand that grasshoppers are adapted to and benefit from grazing by domestic livestock (Prendini et al. 1996) and indigenous game (Pryke et al. 2016). In North American tallgrass prairies, an increasing level of recent grazing by bison also increased grasshopper species richness (Joern 2005). In a global assessment of arthropod response to grazing, it was concluded that grazing can only increase the richness of grasshopper assemblages if it increases heterogeneity of the local environment, and if this increase in heterogeneity is large enough to make up for the loss of resources and increased mortality (Van Klink et al. 2015). This was expected to occur at moderate levels of grazing, and so lend support to the Intermediate Disturbance Hypothesis (Connell 1978). However, because greatest richness was documented in areas with heavy grazing, our findings did not meet these expectations. Grazing and its interaction with fire indeed increases the heterogeneity of vegetation layers across the landscape, with bare patches interspersed with patches of tall grass and grazing lawns (Archibald et al. 2005). These less disturbed vegetation patches are of great value for grasshoppers in an African savanna, especially in a disturbed mosaic (e.g. around a waterhole) where elevated levels of bare ground leaves insufficient cover for grasshoppers to escape predators and intense heat (Samways and Kreuzinger 2001, Gebeyehu and Samways 2003). Management for heterogeneity should be prioritized to provide in the habitat requirements of different taxa - disturbance-tolerant species that benefit from heavy grazing, and less disturbed patches for other more sensitive species.

The effect of vegetation structure. - Full vegetation cover indicative of low levels of disturbance was most important for a suite of sensitive, rare and range-restricted grasshopper species that were of great conservation importance. This contrasts with the majority of grass- hopper species that were more tolerant of disturbance, as indicated by the rich suite of species associated with elevated levels of bare ground, shorter grass, and sparser vegetation cover. Different grasshopper species are also associated with differences in bare ground cover and grass height in African subtropical grassland (Bazelet and Samways 2011a) and savanna (Prendini et al. 1996). Shorter grass benefitted grasshopper species richness in the Swiss Alps (Marini et al. 2009). Although a unique and rich suite of species were associated with greater levels of disturbance, the conservation of sensitive and range-restricted grasshopper species should be prioritized, as they are most vulnerable to local extirpation, especially when considering the large-scale occurrence of heavy grazing.

The effect of rocky outcrops. - Grasslands with more rocky outcrops supported a different and more diverse grasshopper assemblage than grasslands with less rocky outcrops. This concurs with an earlier study, which found surface rockiness to be a good abiotic indicator of grasshopper species richness in a nearby mesic grassland (Crous et al. 2013). Grasshoppers are very sensitive to changes in their local environment, and may use rocky crevices for shelter to escape large temperature fluctuations (Samways 1990). In the United Kingdom, sensitivity of grasshoppers to microclimate was illustrated by their movement away from prevailing winds relative to the direction of a footpath (Gardiner and Dover 2008). Grasshoppers also avoided excessively warm microhabitats devoid of sufficient vegetation cover to prevent them from overheating (Gardiner and Hassall 2009). In the temperate Cape Floristic Region in South Africa, behavior of small, endemic Betiscoides species was influenced by wind intensity, temperature and vegetation height (Matenaar et al. 2014). We argue that rocky outcrops might add to the heterogeneity of microclimatic niches available in the landscape, directly by providing shelter and basking sites, and indirectly by altering the vegetation layer (Crous et al. 2014).

Surrogates of grassland diversity.-Apart from the significant, positive correlation between grasshopper species richness and Shannon $\mathrm{H}^{\prime}$ diversity, we found no meaningful relationships among measures of plant and grasshopper diversity. The proportion of rare, sensitive or range-restricted grasshoppers (GCIn) was not correlated with either grasshopper species richness or Shannon $\mathrm{H}^{\prime}$ diversity. This contrasts with the findings in another study where small grasshopper species with localized distributions were good indicators of species richness in another arthropod group i.e. butterflies (Bazelet and Samways 2012). Also, we found no relationship among plant and grasshopper species richness. In fact, the greatest number of grasshopper species in this study was documented in annually-burned areas with heavy grazing, while this management practice was absolutely detrimental to indigenous plant conservation (Joubert et al. 2014). Noncongruence between plant and grasshopper species richness concurs with findings of a regional study conducted in Inner Mongolia (Hao et al. 2015). In contrast, there was a significant positive relationship between grasshopper and plant species richness in North American tallgrass prairie (Joern 2005) as well as in the Italian Alps (Marini et al. 2009). The absence of significant relationships among measures of plant and grasshopper diversity emphasizes the need to use multiple taxa and multiple measures of diversity to monitor change in grasslands, particularly since the same level of disturbance can cause gains in one taxonomic group and losses in another.

Management recommendations.-Afromontane grassland management should be cognizant of the individual and interactive effects of grazing and fire, as they each uniquely influence the richness and 
composition of grasshopper assemblages. The majority of species are adapted to high levels of disturbance causing them to persist well in grazed landscapes typical for large parts of the African continent. As such, they do not require special conservation measures to be put in place, provided these grasslands are grazed or burned. However, to also conserve the smaller, more sensitive suite of grasshopper species, patches of minimally disturbed grassland (i.e. areas where grazing or burning is difficult, such as rocky outcrops) should be left. Creating a mosaic of patches with different levels of disturbance is necessary to provide habitat for taxa with diverse requirements.

\section{Acknowledgements}

We thank K. Spies and D. van Zyl for field assistance, S. Ntuli for sorting of grasshoppers, C. Bazelet for identification of grasshopper specimens and help with the GCI, C. Grant and F. de Wet for identification of plant specimens, and B. Corcoran, J. Shuttleworth, and O. Sibaya from Mondi, and the Boston community for providing maps, accommodation at field sites, technical assistance, practical advice, and local knowledge. We thank I. Johnson and A. Armstrong for providing expert knowledge specifically pertaining to sampling methods, Mondi for allowing sampling on their properties, and Ezemvelo KZN Wildlife for a permit (OP 4356/2013). This research was financially supported by the Mondi Ecological Network Programme (MENP), the National Research Foundation (NRF) Green Landscapes Programme (Grant number 78652) and the NRF Green Economy grant (Grant number 98055).

\section{References}

Adu-Acheampong S, Bazelet CS, Samways MJ (2016) Extent to which an agricultural mosaic supports endemic species-rich grasshopper assemblages in the Cape Floristic Region biodiversity hotspot. Agriculture, Ecosystems and Environment 227: 52-60. https://doi.org/10.1016/j. agee.2016.04.019

Anderson MJ, Willis TJ (2003) Canonical analysis of principal coordinates: a useful method of constrained ordination for ecology. Ecology 84: 511-525. https://doi.org/10.1890/0012-9658(2003)084[0511:CAO PCA]2.0.CO;2

Archibald S, Bond WJ, Stock WD, Fairbanks DHK (2005) Shaping the landscape: fire-grazer interactions in an African savanna. Ecological Applications 15: 96-109. https://doi.org/10.1890/03-5210

Batáry P, Orci KM, Báldi A, Kleijn D, Kisbenedek T, Erdős S (2007) Effects of local and landscape scale and cattle grazing intensity on Orthoptera assemblages of the Hungarian Great Plain. Basic and Applied Ecology 8: 280-290. https://doi.org/10.1016/j.baae.2006.03.012

Bazelet CS, Samways MJ (2011a) Identifying grasshopper bioindicators for habitat quality assessment of ecological networks. Ecological Indicators 11: 1259-1269. https://doi.org/10.1016/j.ecolind.2011.01.005

Bazelet CS, Samways MJ (2011b) Relative importance of management vs. design for implementation of large-scale ecological networks. Landscape Ecology 26: 341-353. https://doi.org/10.1007/s10980-010-9557-z

Bazelet CS, Samways MJ (2012) Grasshopper and butterfly local congruency in grassland remnants. Journal of Insect Conservation 16: 71-85. https://doi.org/10.1007/s10841-011-9394-7

Bond WJ, Keeley JE (2005) Fire as a global "herbivore": the ecology and evolution of flammable ecosystems. Trends in Ecology and Evolution 20: 387-94. https://doi.org/10.1016/j.tree.2005.04.025

Bond WJ, Midgley GF, Woodward FI (2003) What controls South African vegetation - climate or fire? South African Journal of Botany 69: 79-91. https://doi.org/10.1016/S0254-6299(15)30362-8
Burkepile DE, Thompson DI, Fynn RWS, Koerner SE, Eby S, Govender N, Hagenah N, Lemoine NP, Matchett KJ, Wilcox KR, Collins SL, Kirkman KP, Knapp AK, Smith MD (2016) Fire frequency drives habitat selection by a diverse herbivore guild impacting top-down control of plant communities in an African savanna. Oikos 125: 1636-1646. https://doi.org/10.1111/oik.02987

Calcagno V, De Mazancourt C (2010) glmulti : An R Package for Easy Automated Model Selection with (Generalized) Linear Models. Journal of Statistical Software 34: 1-29. https://doi.org/10.18637/jss.v034.i12

Cardoso P, Erwin TL, Borges PaV, New TR (2011) The seven impediments in invertebrate conservation and how to overcome them. Biological Conservation 144: 2647-2655. https://doi.org/10.1016/j.biocon.2011.07.024

Chesson P (2000) Mechanisms of maintenance of species diversity. Annual Review of Ecology and Systematics 31: 343-366. https://doi. org/10.1146/annurev.ecolsys.31.1.343

Cigliano MM, Braun H, Eades DC, Otte D (2017) Orthoptera Species File. Version 5.0. http://Orthoptera.SpeciesFile.org

Collinge SK, Prudic KL, Oliver JC (2003) Effects of local habitat characteristics and landscape context on grassland butterfly diversity. Conservation Biology 17: 178-187. https://doi.org/10.1046/j.15231739.2003.01315.x

Connell JH (1978) Diversity in tropical rain forests and coral reefs. Science 199: 1302-1310. https://doi.org/10.1126/science.199.4335.1302

Crous CJ, Samways MJ, Pryke JS (2013) Exploring the mesofilter as a novel operational scale in conservation planning. Journal of Applied Ecology 50: 205-214. https://doi.org/10.1111/1365-2664.12012

Crous CJ, Samways MJ, Pryke JS (2014) Grasshopper assemblage response to surface rockiness in Afro-montane grasslands. Insect Conservation and Diversity 7: 185-194. https://doi.org/10.1111/icad.12044

Deacon HJ, Deacon J (1999) Human beginnings in South Africa: uncovering the secrets of the stone age. Altamira Press, California, 224 pp.

Dirsh VM (1965) The African genera of Acridoidea. Cambridge University Press, New York, 579 pp.

Dufrene M, Legendre P (1997) Species assemblages and indicator species: the need for a flexible assymetrical approach. Ecological Monographs 67: 345-366. https://doi.org/10.1890/0012-9615(1997)067[0345:SA AIST]2.0.CO;2

Fartmann T, Krämer B, Stelzner F, Poniatowski D (2012) Orthoptera as ecological indicators for succession in steppe grassland. Ecological Indicators 20: 337-344. https://doi.org/10.1016/j.ecolind.2012.03.002

Fonderflick J, Besnard A, Beuret A, Dalmais M, Schatz B (2014) The impact of grazing management on Orthoptera abundance varies over the season in Mediterranean steppe-like grassland. Acta Oecologica 60: 7-16. https://doi.org/10.1016/j.actao.2014.07.001

Gandar MV (1982) The dynamics and trophic ecology of grasshoppers (Acridoidea) in a South African savanna. Oecologia 54: 370-378. https://doi.org/10.1007/BF00380006

Gardiner T, Dover J (2008) Is microclimate important for Orthoptera in open landscapes? Journal of Insect Conservation 12: 705-709. https://doi.org/10.1007/s10841-007-9104-7

Gardiner T, Hassall M (2009) Does microclimate affect grasshopper populations after cutting of hay in improved grassland? Journal of Insect Conservation 13: 97-102. https://doi.org/10.1007/s10841-007-9129-y

Gebeyehu S, Samways MJ (2003) Responses of grasshopper assemblages to long-term grazing management in a semi-arid African savanna. Agriculture, Ecosystems and Environment 95: 613-622. https://doi. org/10.1016/S0167-8809(02)00178-0

Gebeyehu S, Samways MJ (2006) Topographic heterogeneity plays a crucial role for grasshopper diversity in a southern African megabiodiversity hotspot. Biodiversity and Conservation 15: 231-244. https://doi. org/10.1007/s10531-004-7065-7

Gerlach J, Samways M, Pryke JS (2013) Terrestrial invertebrates as bioindicators: an overview of available taxonomic groups. Journal of Insect Conservation 17: 831-850. https://doi.org/10.1007/s10841-0139565-9 
Güler B, Jentsch A, Apostolova I, Bartha S, Bloor JMG, Campetella G, Canullo R, Házi J, Kreyling J, Pottier J, Szabó G, Terziyska T, Uğurlu E, Wellstein C, Zimmermann Z, Dengler J (2016) How plot shape and spatial arrangement affect plant species richness counts: implications for sampling design and rarefaction analyses. Journal of Vegetation Science 27: 692-703. https://doi.org/10.1111/jvs.12411

Hao S, Wang S, Cease A, Kang L (2015) Landscape level patterns of grasshopper communities in Inner Mongolia: interactive effects of livestock grazing and a precipitation gradient. Landscape Ecology 30: 1657-1668. https://doi.org/10.1007/s10980-015-0247-8

Hauke J, Kossowski T (2011) Comparison of values of Pearson's and Spearman's correlation coefficients on the same sets of data. Quaestiones Geographicae 30: 87-93. https://doi.org/10.2478/v10117-011-0021-1

Joern A (2005) Disturbance by fire frequency and bison grazing modulate grasshopper assemblages in tallgrass prairie. Ecology 86: 861-873. https://doi.org/10.1890/04-0135

Joern A, Laws AN (2013) Ecological mechanisms underlying arthropod species diversity in grasslands. Annual Review of Entomology 58: 19-36. https://doi.org/10.1146/annurev-ento-120811-153540

Johnsen P (1984) Acridoidea of Zambia. Aarhus University Zoological Laboratory, Aarhus, Denmark.

Johnsen P (1991) Acridoidea of Botswana. Aarhus University Zoological Laboratory, Aarhus, Denmark.

Jonas JL, Joern A (2007) Grasshopper (Orthoptera: Acrididae) communities respond to fire, bison grazing and weather in North American tallgrass prairie: a long-term study. Oecologia 153: 699-711. https:// doi.org/10.1007/s00442-007-0761-8

Joubert L, Pryke JS, Samways MJ (2014) Annual burning drives plant communities in remnant grassland ecological networks in an afforested landscape. South African Journal of Botany 92: 126-133. https://doi. org/10.1016/j.sajb.2014.02.009

Joubert L, Pryke JS, Samways MJ (2016a) Past and present disturbances influence biodiversity value of subtropical grassland ecological networks. Biodiversity and Conservation 25: 725-737. https://doi. org/10.1007/s10531-016-1088-8

Joubert L, Pryke JS, Samways MJ (2016b) Positive effects of burning and cattle grazing on grasshopper diversity. Insect Conservation and $\mathrm{Di}$ versity 9: 290-301. https://doi.org/10.1111/icad.12166

Joubert L, Pryke JS, Samways MJ (2017) Moderate grazing sustains plant diversity in Afromontane grassland. Applied Vegetation Science 20: 340-351. https://doi.org/10.1111/avsc. 12310

Kemp WP, Harvey SJ, O'Neill KM (1990) Patterns of vegetation and grasshopper community composition. Oecologia 83: 299-308. https:// doi.org/10.1007/BF00317552

Kirkman KP, Collins SL, Smith MD, Knapp AK, Burkepile DE, Burns CE, Fynn RWS, Hagenah N, Koerner SE, Matchett KJ, Thompson DI, Wilcox KR, Wragg PD (2014) Responses to fire differ between South African and North American grassland communities. Journal of Vegetation Science 25: 793-804. https://doi.org/10.1111/jvs. 12130

Krauss J, Bommarco R, Guardiola M, Heikkinen RK, Helm A, Kuussaari M, Lindborg R, Ockinger E, Pärtel M, Pino J, Pöyry J, Raatikainen KM, Sang A, Stefanescu C, Teder T, Zobel M, Steffan-Dewenter I (2010) Habitat fragmentation causes immediate and time-delayed biodiversity loss at different trophic levels. Ecology Letters 13: 597-605. https://doi.org/10.1111/j.1461-0248.2010.01457.x

Little IT, Hockey PAR, Jansen R (2013) A burning issue: fire overrides grazing as a disturbance driver for South African grassland bird and arthropod assemblage structure and diversity. Biological Conservation 158: 258-270. https://doi.org/10.1016/j.biocon.2012.09.017

Marini L, Fontana P, Scotton M, Klimek S (2007) Vascular plant and Orthoptera diversity in relation to grassland management and landscape composition in the European Alps. Journal of Applied Ecology 45: 361-370. https://doi.org/10.1111/j.1365-2664.2007.01402.x

Marini L, Fontana P, Battisti A, Gaston KJ (2009) Agricultural management, vegetation traits and landscape drive orthopteran and butterfly diversity in a grassland-forest mosaic: a multi-scale approach. Insect Conservation and Diversity 2: 213-220. https://doi.org/10.1111/ j.1752-4598.2009.00053.x
Matenaar D, Bröder L, Bazelet CS, Hochkirch A (2014) Persisting in a windy habitat: population ecology and behavioral adaptations of two endemic grasshopper species in the Cape region (South Africa). Journal of Insect Conservation 18: 447-456. https://doi.org/10.1007/ s10841-014-9654-4

Matenaar D, Bazelet CS, Hochkirch A (2015) Simple tools for the evaluation of protected areas for the conservation of grasshoppers. Biological Conservation 192: 192-199. https://doi.org/10.1016/j.biocon.2015.09.023

McGeoch MA (1998) The selection, testing and application of terrestrial insects as bioindicators. Biological Reviews 73: 181-201. https://doi. org/10.1111/j.1469-185X.1997.tb00029.x

Pausas JG, Ribeiro E (2017) Fire and plant diversity at the global scale. Global Ecology and Biogeography 5: 1-17. https://doi.org/10.1111/ geb. 12596

Prendini L, Theron L-J, van der Merwe K, Owen-Smith N (1996) Abundance and guild structure of grasshoppers (Orthoptera: Acridoidea) in communally grazed and protected savanna. South African Journal of Zoology 31: 120-130. https://doi.org/10.1080/02541858.1996.11 448403

Pryke JS, Roets F, Samways MJ (2013) Importance of habitat heterogeneity in remnant patches for conserving dung beetles. Biodiversity and Conservation 22: 2857-2873. https://doi.org/10.1007/s10531-0130559-4

Pryke JS, Samways MJ (2015) Conserving natural heterogeneity is crucial for designing effective ecological networks. Landscape Ecology 30: 595-607. https://doi.org/10.1007/s10980-014-0096-x

Pryke JS, Roets F, Samways MJ (2016) Wild herbivore grazing enhances insect diversity over livestock grazing in an African grassland system. PLoS ONE 11: e0164198. https://doi.org/10.1371/journal. pone. 0164198

Rowe-Rowe DT, Scotcher JSB (1986) Ecological carrying capacity of the Natal Drakensberg for wild ungulates. South African Journal of Wildlife Research 16: 12-16.

Samways MJ (1990) Land forms and winter habitat refugia in the conservation of montane grasshoppers in southern Africa. Conservation Biology 4: 375-382. https://doi.org/10.1111/j.1523-1739.1990.tb00311.x

Samways MJ, Kreuzinger K (2001) Vegetation, ungulate and grasshopper interactions inside vs. outside an African savanna game park. Biodiversity and Conservation 10: 1963-1981. https://doi. org/10.1023/A:1013199621649

Samways MJ, Pryke JS (2016) Large-scale ecological networks do work in an ecologically complex biodiversity hotspot. Ambio 45: 161-172. https://doi.org/10.1007/s13280-015-0697-x

Schaffers AP, Raemakers IP, Sýkora KV, ter Braak CJF (2008) Arthropod assemblages are best predicted by plant species composition. Ecology 89: 782-794. https://doi.org/10.1890/07-0361.1

Stoner KJL, Joern A (2004) Landscape vs. local habitat scale influences to insect communities from tallgrass prairie remnants. Ecological Applications 14: 1306-1320. https://doi.org/10.1890/03-5112

Torma A, Gallé R, Bozsó M (2014) Effects of habitat and landscape characteristics on the arthropod assemblages (Araneae, Orthoptera, Heteroptera) of sand grassland remnants in Southern Hungary. Agriculture, Ecosystems and Environment 196: 42-50. https://doi.org/10.1016/j. agee.2014.06.021

Van Klink R, van der Plas F, Toos van Noordwijk CGE, WallisDeVries MF, Olff $H$ (2015) Effects of large herbivores on grassland arthropod diversity. Biological Reviews 90: 347-366. https://doi.org/10.1111/ brv. 12113

Weiss N, Zucchi H, Hochkirch A (2013) The effects of grassland management and aspect on Orthoptera diversity and abundance: site conditions are as important as management. Biodiversity and Conservation 22: 2167-2178. https://doi.org/10.1007/s10531-012-0398-8

Wettstein W, Schmid B (1999) Conservation of arthropod diversity in montane wetlands: effect of altitude, habitat quality and habitat fragmentation on butterflies and grasshoppers. Journal of Applied Ecology 36: 363-373. https://doi.org/10.1046/j.13652664.1999.00404.x 